\title{
Multifactorial Traits of SARS-CoV-2 Cell Entry Related to Diverse Host Proteases and Proteins
}

\author{
Jaehwan You ${ }^{1, \dagger}$, Jong Hyeon Seok ${ }^{1, \dagger}$, Myungsoo Joo $^{2}$, Joon-Yong Bae ${ }^{1}$, Jin II Kim ${ }^{1,3}$, Man-Seong Park ${ }^{1,3, *}$ and \\ Kisoon $\mathrm{Kim}^{1, *}$ \\ ${ }^{1}$ Department of Microbiology, Institute for Viral Diseases, Korea University College of Medicine, Seoul 02841 , \\ ${ }^{2}$ School of Korean Medicine, Pusan National University, Pusan 50612, \\ ${ }^{3}$ Biosafety Center, Korea University College of Medicine, Seoul 02841, Republic of Korea
}

\begin{abstract}
The most effective way to control newly emerging infectious disease, such as the severe acute respiratory syndrome coronavirus 2 (SARS-CoV-2) pandemic, is to strengthen preventative or therapeutic public health strategies before the infection spreads worldwide. However, global health systems remain at the early stages in anticipating effective therapeutics or vaccines to combat the SARS-CoV-2 pandemic. While maintaining social distance is the most crucial metric to avoid spreading the virus, symptomatic therapy given to patients on the clinical manifestations helps save lives. The molecular properties of SARS-CoV-2 infection have been quickly elucidated, paving the way to therapeutics, vaccine development, and other medical interventions. Despite this progress, the detailed biomolecular mechanism of SARS-CoV-2 infection remains elusive. Given virus invasion of cells is a determining factor for virulence, understanding the viral entry process can be a mainstay in controlling newly emerged viruses. Since viral entry is mediated by selective cellular proteases or proteins associated with receptors, identification and functional analysis of these proteins could provide a way to disrupt virus propagation. This review comprehensively discusses cellular machinery necessary for SARS-CoV-2 infection. Understanding multifactorial traits of the virus entry will provide a substantial guide to facilitate antiviral drug development.
\end{abstract}

Key Words: SARS-CoV-2, Cell entry, Cellular proteins, Antiviral drugs

\section{INTRODUCTION}

In early March 2020, the World Health Organization declared that the first pandemic caused by coronavirus disease 2019 (COVID-19). The COVID-19 infection sweeps the globe after the first report in Wuhan, China, in December 2019 that severe pneumonia was caused by severe acute respiratory syndrome coronavirus 2 (SARS-CoV-2). By the beginning of March 2021, over 117 million people have been infected with SARS-CoV-2, and over 2.6 million correlated deaths have been reported worldwide (Worldometers.info, 2021).

The rapid progress of whole-genome sequence analysis revealed SARS-CoV-2 has a $29.9 \mathrm{~kb}-$ long, positive-sense single-stranded RNA as a genome and belongs to the genus $\beta$-coronavirus. SARS-CoV-2 shows approximately $79.5 \%$ of nucleotide similarity to SARS-CoV while having $96 \%$ ho- mology to bat coronavirus (Coronaviridae Study Group of the International Committee on Taxonomy of Viruses, 2020; Zhou et al., 2020b). The Coronaviridae family has classified into four genera: $\alpha-, \beta-, \gamma$ - and $\delta$-coronaviruses. Prototypic $\alpha$-coronaviruses include human coronavirus (HCoV)-NL63, HCoV-229E, porcine epidemic diarrhea virus, porcine respiratory coronavirus, and transmissible gastroenteritis virus (TGEV). The $\beta$-coronaviruses include $\mathrm{HCoV}-\mathrm{OC} 43$, middle east respiratory syndrome (MERS)-CoV, murine hepatitis virus, severe acute respiratory syndrome (SARS)-CoV, and SARS-CoV-2, whereas $\gamma$ - and $\delta$-coronaviruses range from avian infectious bronchitis virus (IBV) to bulbul coronavirus, respectively (Coronaviridae Study Group of the International Committee on Taxonomy of Viruses, 2020).

Coronaviruses utilize various membrane proteins on host cells as receptors, including aminopeptidase $\mathrm{N}$ for $\mathrm{HCoV}$ -

\section{Open Access https://doi.org/10.4062/biomolther.2021.048}

This is an Open Access article distributed under the terms of the Creative Commons Attribution Non-Commercial License (http://creativecommons.org/licenses/by-nc/4.0/) which permits unrestricted non-commercial use, distribution, and reproduction in any medium, provided the original work is properly cited.
Received Mar 15, 2021 Revised Mar 26, 2021 Accepted Mar 29, 2021 Published Online Apr 20, 2021

\section{*Corresponding Authors}

E-mail: tigerkis@korea.ac.kr (Kim K), manseong.park@gmail.com (Park MS) Tel: +82-2-2286-1164 (Kim K), +82-2-2286-1312 (Park MS) Fax: +82-2-923-3645 (Kim K), +82-2-923-3645 (Park MS)

${ }^{\dagger}$ The first two authors contributed equally to this work. 
229E and TGEV (Delmas et al., 1992; Yeager et al., 1992), dipeptidyl peptidase 4 (DPP4) for MERS-CoV (Lu et al., 2013), and angiotensin-converting enzyme 2 (ACE2) for SARS-CoV and SARS-CoV-2 (To et al., 2004; Lambert et al., 2005; Lan et al., 2020; Wang et al., 2020b). Host receptor diversity is one of the unique features of coronavirus infection. (Shang et al., 2020a); coronaviruses belonging to the same genus may not use the same receptor as a shared host cell entry portal. For instance, cellular entry of MERS-CoV and SARS-CoV, both of which are belonging genus $\beta$-coronavirus, mediated by DPP 4 and ACE2 as different receptors, respectively. Furthermore, the same receptor can be used by coronaviruses from other genera: ACE2 is used by both HCoV-NL63 ( $\alpha$-coronaviruses) and SARS-CoV ( $\beta$-coronaviruses) (Shang et al., 2020b).

In humans, ACE2 is mainly expressed in lung epithelial cells, enterocytes, arterial endothelial cells, and smooth muscle cells in cardiovascular tissues (Hamming et al., 2004). The ACE2 has been recognized as a pivotal player in the SARSCoV-2 transmission pathway on the cell membrane. Spike (S) protein, a viral envelope glycoprotein of the SARS-CoV-2, has a crucial role in viral entry into the cell via viral attachment and membrane fusion. The $\mathrm{S}$ protein undergoes significant conformational changes from metastable pre-fusion conformations to stable post-fusion conformations. After binding or interaction with various cellular proteins, viral and host cell membrane fusions are mediated by their structural affinity ( $\mathrm{Li}$, 2016; Lan et al., 2020; Walls et al., 2020; Yan et al., 2020). Engagement of the $S$ protein to the receptors induces endocytosis or the fusion between the viral envelope and the host cell membrane. This process is the most critical step in determining host compatibility and transmissibility of SARS-CoV-2.

This review aims to collate and organize the latest information on host proteins involved in the cell entry process. Scrutiny of the relationship between the host factors and viral proteins can help further understand of emerging SARS-CoV-2. Sophisticated information regarding invasive cellular traits can also provide an insight for designing antiviral drugs targeting virus-host protein interaction to perturb the virus entry.

\section{VIRAL SPIKE PROTEIN}

The $S$ protein is a trimeric glycoprotein embedded in the viral envelope and plays an essential role in viral binding to receptors. Because the S protein determines the tropism of viral infection, numerous efforts on functional as well as structural studies have been made, and its three-dimensional structure was quickly elucidated by cryo-EM analysis (Coutard et al., 2020; Lan et al., 2020; Ou et al. 2020; Walls et al., 2020; Wrapp et al., 2020). Most coronaviruses contain S protein divided into S1 and S2. The S1 subunit interacts with the host receptor, and the $\mathrm{S} 2$ subunit is involved in fusion with the host cell membrane after receptor binding. When the S1/S2 conjunction site in the $S$ protein is processed by the cellular factors, including proteases, significant structural changes occur concomitantly.

In the S2 region, an additional protein cleavage occurs to form S2'. This process also plays an essential role in determining the efficiency of viral infection to the target cells. Surprisingly, unlike SARS-CoV, the SARS-CoV-2 contains an additional protease recognition site in the S1/S2 cleavage area (Andersen et al., 2020; Wang et al., 2020a). The furin, a protease ubiquitously expressed across all the tissue, cleaves an additional protease recognition site in the $S$ protein of the SARS-CoV-2 that contributes to differential behavior from SARS-CoV (Wang et al., 2020a). As multi-basic cleavage site (MBS), which readily cleaves HA0 into HA1 and HA2 by unspecified host proteases in the hemagglutinin (HA) of a highly pathogenic influenza virus plays a crucial role in the pathogenesis of the virus (Alexander and Brown, 2009; Suguitan et al., 2012), the furin recognition site in the S protein of SARS-CoV-2 significantly contributes to the viral pathogenesis (Coutard et al., 2020).

The S proteins of SARS-CoV and SARS-CoV-2 show approximately $76 \%$ genetic similarity. In contrast, the receptorbinding domain (RBD) in the S protein, responsible for binding to host receptors, sustains only a $50 \%$ similarity between two types of SARS-CoV. Of note, both SARS-CoV-2 and SARSCoV utilize an identical type 1 membrane protein, ACE2, their primary cellular receptor (Wu et al., 2020).

To bind ACE2, the RBD of $S$ protein required the receptoraccessible conformation that shifts RBD conformation towards an ACE2 because of hidden and buried receptor-binding site (RBS) in the interspace of protomers (RBD closed) (Fig. 1). When the RBD conformation changes to OPEN state, RBD loses the interactions with S2 or other protomers, and RBS is exposed and then ready for the interaction with ACE2. Therefore, the two conformations of RBD, open and closed states, were related to viral attachment and infectivity (Walls et al., 2020; Yan et al., 2020). A substitution of D614G increases infectivity due to disturb interprotomer interactions of a salt bridge between Asp-614 in the C-terminal domain 2 (CTD2) and Lys-854 in the fusion peptide proximal region (FPPR). The RBD conformational alteration with glycine at the position in 614 led the slight shift to the opened status and enhanced ACE2 binding-competency that allowed higher accessibility to the receptor than D614 (Yurkovetskiy et al., 2020; Zhang et al., 2021).

The binding of SARS-CoV-2 RBD to ACE2 involves 13 hydrogen bonds contributed by multiple tyrosine residues, two salt bridges, and the glycan at Asn-90 of ACE2, which is very similar to the binding of SARS-CoV to ACE2 (Yuan et al., 2017). The S protein of SARS-CoV-2 has also been predicted to contain $22 \mathrm{~N}$-linked glycosylation motifs. If glycosylation occurs as expected, it is likely to affect $\mathrm{S}$ protein cleavage due to altered accessibility of host cellular proteins and neutralizing antibody activity after viral infection (Walls et al., 2020). Exploring additional cellular elements, which facilitate viral entry with the viral $S$ protein, a novel cell entry facilitator, neuropilin-1 (NRP1), has recently been recognized (Daly et al., 2020). With the premise that the relevance to cell entry is clarified, this cellular protein might be an additional target molecule for developing antivirals.

Since SARS-CoV-2 uses RNA as a genome, continuous and sporadic nucleotide mutations throughout the viral genome accumulate during genome replication (Denison et al., 2011). To implement sharing of the viral genomic information, scientists and public health agencies deposit viral genomic sequences obtained from their territory to the public database, Global Initiative for Sharing All Influenza Data (GISAID). Significant mutations on the S protein-including D614G, a typical characteristic of the $\mathrm{G}$ clade, are already notified globally through the GISAID. Recently, SARS-CoV-2 VOC (variant of concern) 202012/01 variant harboring multiple alterations 


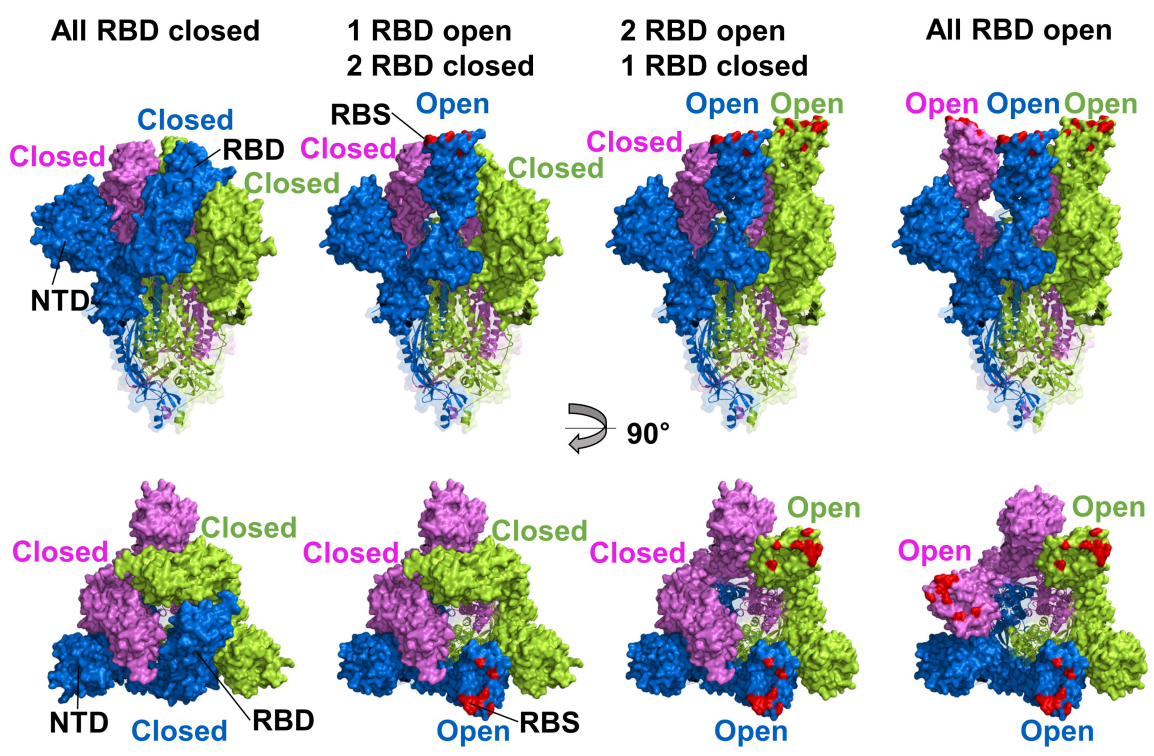

Fig. 1. RBD conformations of SARS-CoV-2 S protein. Cryo-EM structure of SARS-CoV-2 S protein trimer (PDB ID 6VXX and 6VYB) drawn by surface and ribbon diagrams, S1 and S2 domains, respectively. The three protomers are colored blue, pink, and green, and the human ACE2 receptor binding site (RBS) was highlighted by red color, respectively. Side (upper panel) and top (lower panel) views of the S protein structures are divided by open and closed configurations of the RBD. RBS is hidden and buried in protomers' interspace (RBD closed) and not accessible to the receptor. When the RBD status has opened, RBS is exposed and ready to interact with the ACE2 receptor. The figures were created with PyMOL (https://www.pymol.org/).

(deletion 69-70, deletion 144, N501Y, A570D, D614G, P681H, T716I, S982A, and $\mathrm{D} 1118 \mathrm{H}$ ) have been identified from viral genomic sequencing in the United Kingdom (UK). Simultaneously, another variant lineage with E484K and multiple nonsynonymous mutations in the $S$ protein, distinct from the UK variant, was reported from South Africa and Brazil. These distinct variants were then colloquially designated as B.1.1.7, B.1.351, and P.1 lineages from the UK, South Africa, and Brazil, respectively (Mwenda et al., 2020).

Based on the identical mutation sites of E484K and N501Y retained in three different variant lineages localized in the receptor binding motif that binds to human ACE2. E484K substitution altered the hydrogen bonds or charged interactions that might effectively escape the neutralizing monoclonal antibodies, BD23, C119, and P2B-2F6. Moreover, E484K mutation decreased the neutralizing activity of vaccinated human sera with the Pfizer mRNA (BNT162b2) in a pseudotyped lentiviral virion system (Tada et al., 2021; Wibmer et al., 2021). On the other hand, N501Y substitution modulated the interactions between RBD and ACE2, affecting the higher transmission efficiency. Y501 showed four to ten times higher binding affinity with ACE2 than N501 because of a significantly low Koff rate and slightly high Kon rate of ACE2 interaction (Tian et al., 2021). Therefore, these variants are of great concern for potentially inducing vaccination failure, increased numbers of infections, and reduced efficacy of antivirals or antibody therapeutics.

\section{HOST PROTEINS}

Various host factors are involved during viral infection, including receptor(s), membranous proteases, and other cell surface proteins (Fig. 3). Herein, we will discuss the charac-
Box 1. Currently known primary characteristics of the S protein of SARS-CoV-2 (Fig. 2).

- The S protein ( 180 kDa) of SARS-CoV-2 consists of a trimeric glycoprotein structure in a viral envelope.

- The S protein contains two domains, S1 and S2, and plays a critical role in cell entry binding to the host cell receptor, ACE2.

- Open status of RBD in the S protein led to the exposure of the RBS (receptor binding site) and ready to interact with ACE2.

- $S$ protein binding to the ACE2 promotes viral envelope and cell membrane fusion and elicits structural changes.

- Neuropilin-1 (NRP1) was suggested as a secondary cellular receptor factor that may facilitate virus entry into the cell.

- RBD in the $S$ protein is essential for recognizing receptors and generating neutralizing antibodies.

- Notable mutations in the S protein were identified and retained at the receptor binding motif, which may neutralize or reduce currently available vaccines and antivirals.

- The development of antiviral drug strategies to reduce viral entry has focused on the inhibition of interactions between the $S$ protein and receptor machinery mediated by various host proteins. 

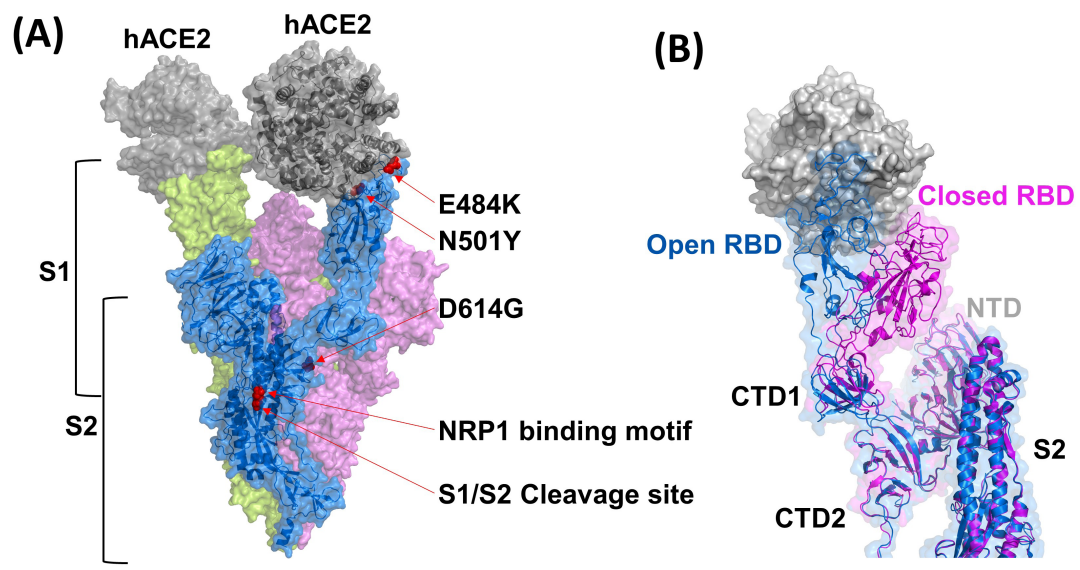

Fig. 2. Characteristics of each domain and motif represented on S protein of SARS-CoV-2 involving host cell entry. (A) Designated surface and ribbon diagrams of trimeric spike proteins in the SARS-CoV-2. Each protomer's marginal views that play a critical role in cell entry binding to host cell receptors are colored as pink, blue, and green, respectively (PDB ID 7KMZ). Accessibility to the ACE2 receptor of the three receptor binding sites (RBDs) are colored blue and green when the RBD is open status, whereas closed RBD is colored as pink. Neuropilin-1 (NRP1) binding motif, as a putative cellular entry facilitator, furin cleavage site (S1/S2), and notable mutations in the S protein (N501Y, D614G, and E484K) were marked with red arrows. (B) Superimposed image of opened (blue) and closed (magenta) configurations of the RBD in S1 regions directly interacting with the ACE2. Structural alteration of the NTD (N-terminal domain) and S2 domain of the spike protein after binding ACE2 is negligible. The human ACE2 receptor is colored gray. (PDB ID 7KMZ). The figures were created with PyMOL (https://www.pymol.org/).

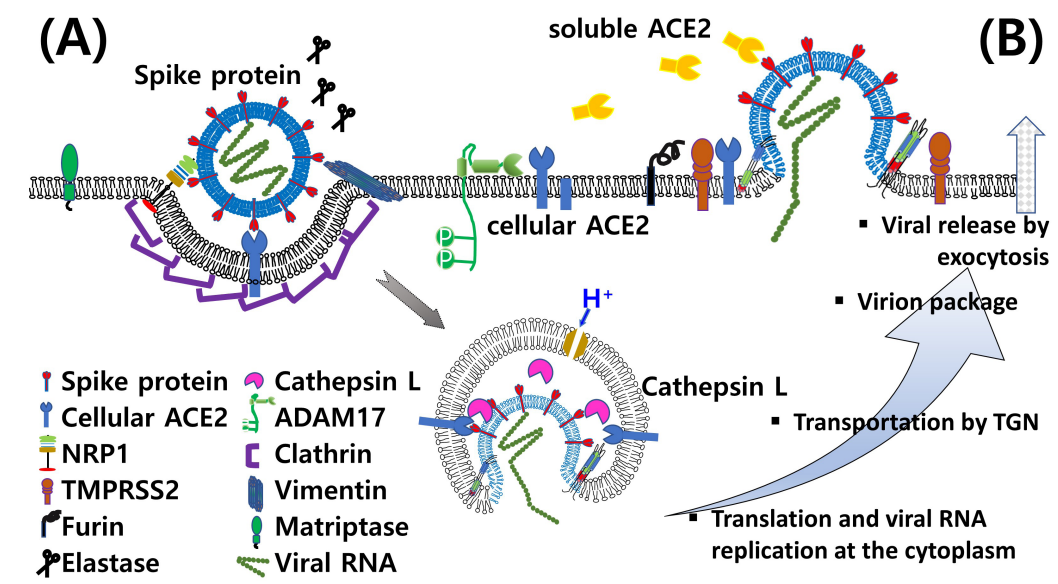

Fig. 3. Schematic diagram of postulated multifactorial SARS-CoV-2 cell entry through endocytosis (A) and direct membrane fusion (B). The SARS-CoV-2 preferentially utilizes ACE2 (angiotensin converting enzyme 2) as a cellular receptor to recognize susceptible cells. Another host factor, NRP1, may facilitate cellular receptors for the virus' cell entry; once the NRP1 interacts with trimerized viral spike proteins, entry machinery induces conformational alteration of spike proteins in the cell membrane. A variety of membranous proteins participate in the endocytic pathway and/or virus-to-cell fusion process is illustrated. Each cellular and viral factor described in the figure is not on a scale. ACE2, angiotensin converting enzyme 2; TMPRSS2, transmembrane protease serine subtype 2; NRP1, neuropilin-1; ADAM17, a disintegrin and metalloproteinase 17 ; TGN, trans-Golgi network.

\section{Angiotensin converting enzyme 2 (ACE2)}

Viruses are obligate intracellular parasites; thus, exploiting a host is essential for their reproduction. The first step of virus replication is to invade cells. The host cell surface proteins to which a virus binds are critical in determining the viral susceptibility of the host. Both SARS-CoV-2 and SARS-CoV are reported to use ACE2 as a receptor (Lan et al., 2020; Shang et al., 2020b). ACE2 was discovered in the year 2000 as a membrane-bound enzyme that antagonizes the function of ACE, thereby contributing to decreasing vascular pressure (Donoghue et al., 2000). ACE2 is a type 1 membrane pro- tein, forming a homodimer on the cell membrane. As a renin-angiotensin system (RAS) member, ACE2 contributes to decreased blood pressure by breaking down angiotensin II, a hypertensive substance, angiotensin, and hypotensive substance (Ferrario et al., 2005; Wysocki et al., 2010; Li, 2016).

ACE2 was identified as a receptor for the SARS-CoV, a causative agent of the SARS epidemic in 2003 (Li et al., 2003). According to the Human Protein Atlas (HPA), ACE2 is highly expressed in the small intestine, kidney, and prostate. The finding that ACE2 is also abundantly expressed in lung alveolar epithelial type II cells (AECII) is likely a significant 


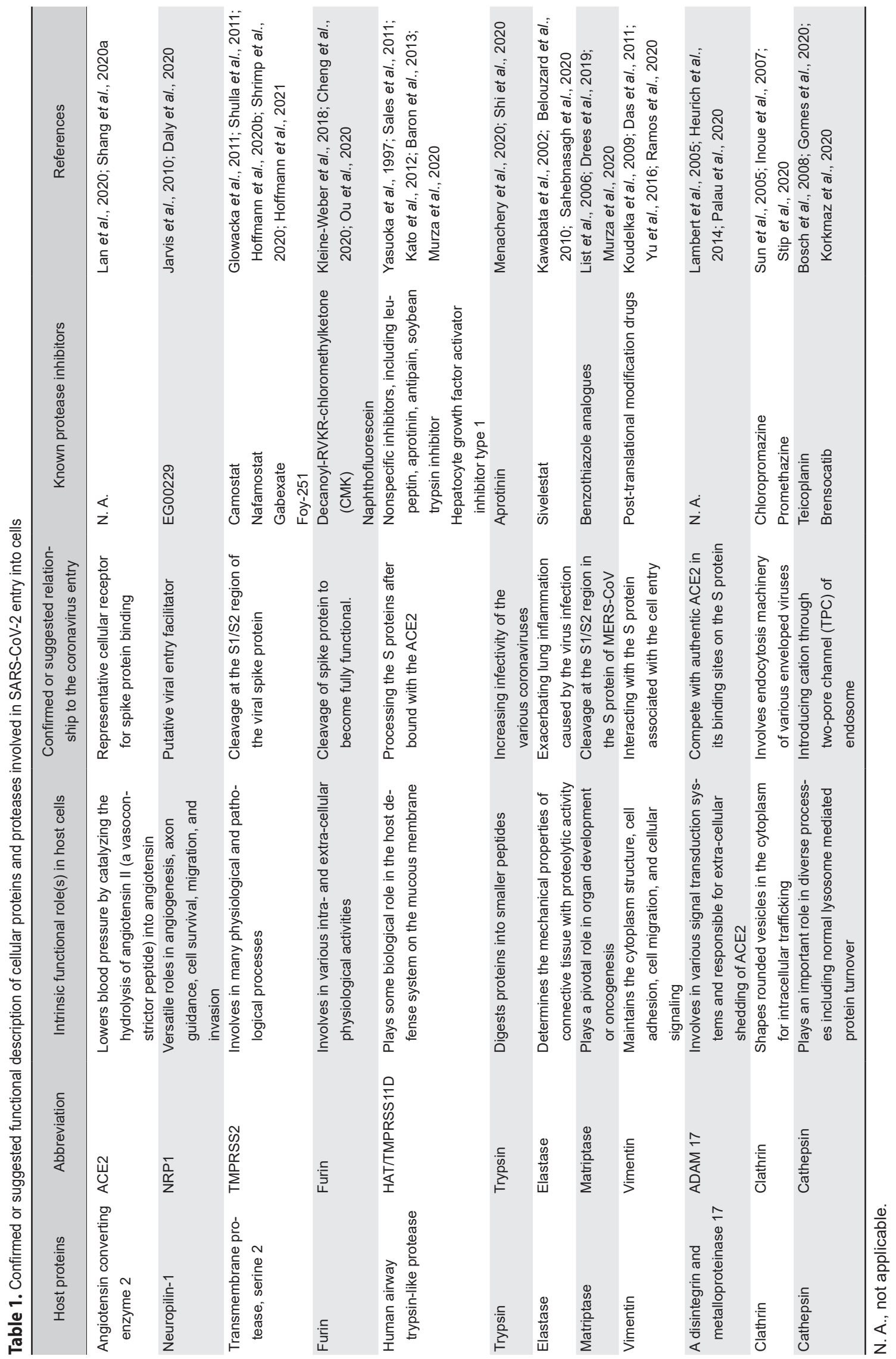


aspect of SARS-CoV-2 viral infection, which causes severe pulmonary disease (Kuba et al., 2006).

The peptidase domain (PD) of ACE2 is the counterpart of the RBD in the $S$ protein. The binding of PD to the RBD causes structural changes in the $S$ protein, exposing the cleavage sites at the S1/S2 or adjacent regions, which are attacked by host cellular proteases, and prompting the conversion from pre-S to post-S states (Li et al., 2003; Heurich et al., 2014). Host proteases involved in this process include transmembrane serine protease 2 (TMPRSS2) or human airway trypsin-like protease (HAT). While cleaving the S protein, these enzymes also digest ACE2 at the 697-716 residues, facilitating the $S$ protein and fusion processing between the virus and host cells (Heurich et al., 2014).

Given the role of ACE2 in regulating blood pressure, it is conceivable that hypertension could affect viral infection outcomes. For instance, animals administered with ACE inhibitors or angiotensin receptor blockers (ARBs) showed an increased expression of ACE2 in the lung and kidney tissues (Ferrario et al., 2005), and some severe cases of SARS-CoV-2 infection accompany hypertension, chronic nephritis, cardiovascular diseases, and diabetes (Zhou et al., 2020a).

However, the report of the enhanced expression of ACE2 after ACE inhibitors or ARBs treatment remains confirmed, and there is no evidence that similar treatments increase ACE2 expression in human lung tissues (Kuba et al., 2006). Notably, various cases of hypertension, diabetes, and chronic kidney diseases found among patients with severe viral infections could be statistically biased because such studies lack information concerning various comprehensive analysis factors, including age, gender, underlying pulmonary disorders, and the attributable disease burden of viral infection on death (South et al., 2020). Currently, the health risks imposed by the withdrawal of antihypertensive drugs seem to outweigh those of viral infection (Danser et al., 2020). Since the level of ACE2 was decreased after infection of SARS-CoV on lung cells (Kuba et al., 2006), SARS-CoV-2 is likely to reduce ACE2 expression in lung tissue. It is imperative to investigate other effects of hypertension, kidney diseases, and diabetes on coronavirus infection.

ACE2 is also found in a soluble form in blood and urine related to extracellular shedding of ACE2. A disintegrin and metalloproteinase 17 (ADAM17) is reported to be involved in this process (Wysocki et al., 2010; Mizuiri and Ohashi, 2015; Perico et al., 2020). This extracellular, truncated ACE2 maintains carboxypeptidase activity and the ability to bind to viral $S$ protein (Jia et al., 2009). It was reported that when treated with recombinant water-soluble ACE2 (SACE2), cultured cells were protected from SARS-CoV infection (Batlle et al., 2020). Similarly, increased levels of sACE2 following ADAM17 treatment lowered SARS-CoV infectivity. Therefore, it is possible that cleaving off ACE2 from cell membranes before the attachment of the $S$ protein could be a strategy to reduce SARS-CoV-2 infection. However, any potential antiviral effect of SACE2 requires careful study because administering sACE2 could disturb the complex regulatory loop of RAS (Lambert et al., 2005; Danser et al., 2020).

Sequence diversity and variable gene expression of ACE2 are well-documented among different populations (Nedelkov, 2008; Hussain et al., 2020). Single-cell RNA sequencing has shown variable expression of ACE2 among Asians, Caucasians, and Africans (Zhao et al., 2020). Contrary to these reports, sequencing of RNA extracted from human lungs revealed no statistical difference in ACE2 expression between gender and different races (Li et al., 2020; Wu et al., 2021). While these contradictory results could be due to differences in study design and analysis methods, the relation between ACE2 expression and the susceptibility to viral infection needs to be verified.

Although ACE2 is a primary rendezvous point on the cell for infection of SARS-CoV-2, it remains unclear whether the physiologic function of ACE2 impacts the infectivity of SARSCoV-2. The signaling cascade downstream of ACE2 may be an alternative contributor to viral infectivity or productivity. It also remains to be clarified whether dysfunctional ACE2 contributes to damage inflicted on lung parenchymal cells and lung tissue, putting an additional disease burden on the host. Further elucidation for the precise role of ACE2 in viral infection could provide insight on how to strategize suppression of SARS-CoV-2 infection.

\section{Neuropilin-1}

While most studies have focused on ACE2 as a unique cell receptor for viral entry, a novel cell entry facilitator, neuropilin-1 (NRP1), has recently been identified (Cantuti-Castelvetri et al., 2020; Daly et al., 2020). NRP1 is a well-known cellular membranous protein involved in various intracellular signaling and catalytic reactions (Roth et al., 2016). According to the HPA, NRP1 is widely expressed throughout the entire body and mainly distributed in the respiratory tract's epithelial surface layer, which is an outpost of the cell entry for this virus (Thul et al., 2017).

Unlike SARS-CoV, the S protein of SARS-CoV-2 possesses a furin cleavage site located adjacent to the S1/S2 junction containing an R-X-X-R motif, in which $\mathrm{R}$ and $\mathrm{X}$ represent glycine and any amino acid residue, respectively. An amino acid residue " $\mathrm{R}$ " is constantly exposed at the C-terminus of the $\mathrm{S} 1 /$ $\mathrm{S} 2$ cleavage site by the host protease furin, commonly known as the C-end rule (CendR) (Teesalu et al., 2009). Reactivity of the R-X-X-R configuration with NRP1 was proposed, and it was recently shown that the CendR motif present in the S1 protein of SARS-CoV-2 binds to the b1 region of NRP1 (Daly et al., 2020).

Further investigation was conducted using the pseudovirus or the SARS-CoV-2 mutant lacking the furin recognition site to understand how viral infectious interference resulted in reciprocal interaction between the CendR motif of the $S$ protein b1 domain by NRP1 (Cantuti-Castelvetri et al., 2020). It was confirmed that viral infectivity was significantly decreased when the CendR motif in the S1 region of the S protein was removed. Additional evidence identified that a monoclonal antibody capable of binding to the b1 region of NRP1 could also reduce infectivity. This research clearly shows that NRP1 plays a potential cofactor role during viral cell entry through interaction with the SARS-CoV-2 S protein's unique structure.

However, several questions remain to be answered if NRP1 is considered a secondary cellular receptor in addition to ACE2, which has been initially shown to contribute to the determination of infectivity and transmissibility. First, unlike SARS-CoV, MERS-CoV contains a furin recognition site in its $S$ protein. The underlying reason(s) why infectivity and transmissibility of MERS-CoV differ from SARS-CoV-2 requires further investigation. Second, it is necessary to elucidate how the furin-cleaved motif of S1 bound to the NRP1 b1 region is 
involved in viral cell entry using ACE2 as an essential prerequisite or an accessory structural behavior that assists in the $S$ protein and ACE2 interaction. Finally, epidemiologic studies should be conducted on how the characteristics of NRP1, which are widely distributed in various tissues, especially within blood vessels, affect disease exacerbation of SARS-CoV-2 infected tissues as a secondary cellular receptor.

Compiling the appropriate knowledge on the importance and function of NRP1 within the infectivity and spread of the virus may implicate it as a meaningful target when developing antiviral drugs that inhibit the interaction between virus and cells.

\section{Transmembrane protease serine subtype 2 (TMPRSS2)}

When the S protein of SARS-CoV-2 is bound to ACE2, fusion mediated by host proteases ensues from the viral envelope and cell membrane. Host proteases mediate this process, and a series of structural changes in the $S$ protein subsequently occur, including 1) cleavage at the S1/S2 region of the viral S protein, 2) breakage at the S2' in S2, which results in the exposure of the fusion peptide, and 3) the formation of the heptad structure of heptad repeat 1 (HR1) and 2 (HR2) (Xia et al., 2020).

No correlation was established between the expression levels of ACE2 and infectivity of SARS-CoV in 2003 (Ding et al., 2003; To and Lo, 2004). Of note, cellular invasion by influenza virus occurs via membrane fusion, similar to that of SARSCoV. The viral HA, influenza virus, is processed by various host proteases, including trypsin, tryptase Clara, mini-plasmin, HAT, and TMPRSS2. Similar speculation was suggested that other protein cleavage after the SARS-CoV binding to ACE2 might be necessary (Bertram et al., 2011). Several studies showed that TMPRSS2, a type II membranous serine protease, participates in cleaving the S1/S2 region of SARS-CoV (Glowacka et al., 2011; Shulla et al., 2011). Similarly, the infectivity of SAR-CoV-2 in green monkey kidney (Vero) cells was enhanced by overexpression of TMPRSS2 (Matsuyama et al., 2020), suggesting a critical role of TMPRSS2 for the infectivity of SARS-CoV-2. Thus, several protease inhibitors such as camostat, nafamostat, gabexate, and Foy-251, which are known to involve disruption of TMPRSS2 proteolytic activity, are under clinical trials as prominent antiviral therapeutics (Hoffmann et al., 2020b; Shrimp et al., 2020; Hoffmann et al., 2021). Nevertheless, the virus can infect cells with low levels or no TMPRSS2 being expressed (Matsuyama et al., 2020). These results suggest that along with TMPRSS2, successful infection of SARS-CoV-2 requires additional proteases, including furin.

Indeed, SARS-CoV-2, unlike SARS-CoV or other $\beta$-coronaviruses, contains a unique proteolytic region near the $\mathrm{S} 1 /$ S2 cleavage site, which can be recognized by other cellular proteases rather than TMPRSS2 through viral genomic analysis (Coutard et al., 2020; Wang et al., 2020a). Hence, it is necessary to take multiple targets when developing protease inhibitors that interrupt viral infection.

\section{Furin}

The S protein in SARS-CoV-2 harbors a furin cleavage site in the S1/S2 region, which does not exist in SARS-CoV (Kleine-Weber et al., 2018; Ou et al., 2020; Wang et al., 2020a). Furin is one of nine serine proteases that belong to the calcium-dependent proprotein-converting enzymes (proprotein convertases; PCs), involved in various intracellular and extracellular physiological activities (Seidah and Prat, 2012). The substrates of the PCs include hormones, growth factors, receptors, conjugates, and viral glycoproteins (Seidah and Chrétien, 1999).

Furin recognizes and cleaves the R-X-X-R motif in a calcium-dependent manner where $\mathrm{R}$ and $\mathrm{X}$ represent glycine and any amino acid residues, respectively. (Nakayama, 1997). Furin is also involved in the processing of bacterial toxins and various cellular and viral proteins. For instance, furin performs proteolysis upon the glycoproteins of HIV, measles, RSV, dengue, and Zika viruses to engender the structural stability of the corresponding proteins, which contributes to the maintenance of viral infectivity (Thomas, 2002; Hoffmann et al., 2017). It was suggested that high furin expression in human lung cells correlated with more severe respiratory viral infection (Mbikay et al., 1997; Bassi et al., 2017).

Consistent with this hypothesis, several HCoVs, such as HCoV-OC43, MERS-CoV, and HCoV-HKU1, all of which cause respiratory infections to varying degrees, contain a furin recognition motif $[(R / K)-(2 X) n-(R / K) \downarrow]$ in the $S 1 / S 2$ cleavage region (Millet and Whittaker, 2014; Le Coupanec et al., 2015). However, the S1/S2 region of SARS-CoV contains an AYTM amino acid motif, which is recognized and cleaved by elastase, cathepsin L, and TMPRSS2 of S proteins (Bosch et al., 2008; Matsuyama et al., 2010; Millet and Whittaker, 2015).

SARS-CoV-2 can successfully proliferate even in cells that express low levels or an absence of the specific protease known to be essential for priming the binding of the $S$ protein to the ACE2, suggesting that an additional protease recognition motif is critical for the enhanced infectivity exhibited by SARS-CoV-2 likely traits of highly pathogenic avian influenza viruses (Munster et al., 2010; Böttcher-Friebertshäuser et al., 2014; Luczo et al., 2015; Scheibner et al., 2019).

Given that furin is expressed in most human tissues, it is conceivable that SARS-CoV-2 infection could occur throughout the body, not confined to the respiratory tract. However, the presence of a furin site in the $S$ protein could not explain the characteristic of SARS-CoV-2 infectivity because less rampant MERS-CoV also has a furin cleavage site in the $S$ protein (Hoffmann et al., 2020a; Shang et al., 2020a). The distinctive infectivity and transmissibility of SARS-CoV-2 may result from combined functions of cellular proteases, including furin. A detailed understanding of the role of furin during the initial and subsequent viral infection to a cell and neighboring cells by SARS-CoV-2 has likely led us to explore therapeutic measures against SARS-CoV-2 infection successfully.

\section{Human airway trypsin-like protease (HAT)}

HAT, or TMPRSS11D, is a type 2 transmembrane serine protease known to cleave $\mathrm{HA}$ in seasonal and avian influenza viruses (Matsushima et al., 2006; Bugge et al., 2009). HAT also participates in cleavage processing in the $S$ protein of SARS-CoV and MERS-CoV (Belouzard et al., 2009; Shirato et al., 2013). HAT cleaves R667 (near the S1/S2 cleavage site) of the S protein of SARS-CoV (Bertram et al., 2011). Unlike TMPRSS2 that recognizes R677 at the S1/S2 cleavage site and R797 at the S2' site, both virus-cell and cell-cell fusion are facilitated, HAT is thought to be mainly involved in cell-cell fusion within SARS-CoV infection (Belouzard et al., 2009).

However, it is unclear how HAT regulates the infectivity of SARS-CoV-2. It seems that its function is dispensable and 
quickly compensated for by other enzymes in that the genetic ablation of HAT did not affect the development of C57BL/6 mice (Bertram et al., 2011; Sales et al., 2011). When experimental animal models with genetically knock-downed a series of protease genes were available, the effects of proteases on the infectivity of SARS-CoV2 and other similar viruses could be further elucidated. Nevertheless, given that broad-spectrum protease inhibitors could compromise SARS-CoV-2 infectivity to some degree, proteases involved in virus-cell fusion should be investigated as therapeutics against SARS-CoV-2 (Sales et al., 2011; Huynh et al., 2020).

\section{Trypsin}

Trypsin is a prototypic serine endopeptidase that cleaves arginine $(\mathrm{R})$ or lysine $(\mathrm{K})$ residues at neutral $\mathrm{pH}$. Although the viral $S$ protein contains these amino acids at numerous sites, trimeric aggregation in the S protein allows only a few trypsin recognition sites to be exposed to the protease. It was reported that trypsin recognizes and cleaves R667 in the S protein of SARS-CoV (Li et al., 2006; Shirato et al., 2013; Huynh et al., 2020). Exogenous treatment of trypsin to African green monkey kidney cells (Vero) enhanced the infectivity of various coronaviruses approximately 100-1000 times, suggesting that the infectivity of SARS-CoV can be augmented by trypsin (Kam et al., 2009).

Conversely, trypsin treatment before the virus infection decreases SARS-CoV infectivity 10 - to 100 -fold by cleaving off a part of the $S$ protein (Matsuyama et al., 2005). Thus, it is possible that binding to ACE2 triggers structural changes in the $S$ protein, which could then be cleaved by trypsin, leading to increased infectivity (Yao et al., 2004). Similar to the trypsin activity increasing influenza virus infectivity, it has been reported that the animal coronavirus infectivity in HKU-5 with trypsin increased to levels beyond the natural species barrier (Menachery et al., 2020).

The most pronounced difference between SARS-CoV and SARS-CoV-2 is their ability to form a syncytium with adjacent cells (Qian et al., 2013; Buchrieser et al., 2020). In cell-cell fusion systems using virus-like particles, the S protein of SARSCoV-2 can induce cell fusion between infected and target cells without an exogenous proteolysis enzyme (e.g., trypsin); however, in the case of SARS-CoV, this fusion phenomenon between $S$ proteins does not occur. The function of cell-cell fusion and the formation of syncytia with adjacent cells due to structural changes of the viral S proteins play an essential role in determining the cell tropism of the virus (Matsuyama, 2011). Therefore, accessibility of the protease, which can induce a structural variation of the viral S protein together with the cell membrane receptors, will be a critical factor in determining viral infectivity and host selectivity of the virus (Menachery et al., 2020; Ou et al., 2020).

\section{Elastase}

Elastase is expressed as part of the inflammatory response due to viral infection and secreted from neutrophils during severe pneumonia or pseudomonas, resulting in multiple infections within the lungs (Kawabata et al., 2002). Elastase cleaves T795 proximal to the fusion peptide (S2'/R797) in the S2 region of SARS-CoV during the invasion of the virus into the host cell (Matsuyama et al., 2005; Belouzard et al., 2010). In general, elastase is less effective than trypsin in cleaving the $S$ protein than in the entry machinery. Still, a study of the fusion peptide of the T795A mutation showed that the fusion efficacy of the $S$ protein was increased by elastase (Ami et al., 2008; Belouzard et al., 2010).

Despite increased elastase expression levels, this may not directly affect a structural change of the $S$ protein. Instead, Pseudomonas spp., co-infected with SARS-CoV via opportunistic infection, likely increases elastase production, which exacerbates lung pathology along with SARS-CoV (Yao et al., 2004; Ami et al., 2008). Other possible roles of elastase within lung pathology can be further speculated. Elastase activity loosens the structural integrity in lung tissues, increases vascular permeability of lung cells, and promotes the secretion of proinflammatory cytokines (Kawabata et al., 2002; Belouzard et al., 2010). Unlike TMPRSS2 and trypsin, the elastase appears not directly to impact structural changes of $S$ proteins. However, it may play an important role in exacerbating lung inflammation caused by virus infection (Ami et al., 2008).

\section{Matriptase}

Matriptase, a type 2 transmembrane serine protease, is highly expressed in epithelial cells within the respiratory tract and the human bronchial epithelial cancer cell line Calu-3. It is well known that matriptase cleaves $\mathrm{HAO}$ of the influenza virus into HA1 and HA2 by recognizing sites of RSSR/RSRR in the MBS motif. Thus, when matriptase expression was inhibited in Calu-3 cells, the infectivity of influenza viruses was considerably decreased (Kawabata et al., 2002; Baron et al., 2013).

Unlike the proteolytic function of matriptase against HA of influenza viruses that has been well described, the exact role in the cleavage mechanism for various coronaviral S proteins remains explored. Instead, intermittent studies implicate that matriptase may be involved in cleavage at the S1/S2 region in the S protein of MERS-CoV, which is the target of furin and TMPRSS2 (Hamilton et al., 2012; Hoffmann et al., 2020a). Matriptase is known to be expressed in various tissues, implying that this protease plays a pivotal role in organ development or oncogenesis (List et al., 2006; Drees et al., 2019). However, it remains to be determined whether matriptase plays a crucial role in the pathogenesis and infectivity of coronaviruses, including SARS-CoV-2.

\section{Vimentin}

Vimentin is a type 3 intermediate filamentous protein essential for maintaining cytoplasm structure, cell adhesion, cell migration, and cellular signaling (Mor-Vaknin et al., 2003; Vijay, 2020). Vimentin can also be exposed outside the cell membrane, facilitating the infection of porcine reproductive and respiratory syndrome virus and Japanese encephalitis virus (JEV) (Kim et al., 2006; Koudelka et al., 2009; Yu et al., 2016).

Vimentin is distributed around the S protein and ACE2 receptor complex. It has been associated with host cell entry by directly interacting with the $S$ and $E$ proteins in SARS-CoV and JEV, respectively (Das et al., 2011; Yu et al., 2016). Given the critical of host proteases, further studies are necessary to fully understand how surface vimentin works together with various host proteases to facilitate virus infection potentially.

\section{A disintegrin and metalloproteinase-17 (ADAM17)}

ADAM17, also known as TNF- $\alpha$-converting enzyme, is a type 1 transmembrane protease whose identified targets are approximately 80 proteins, including cytokines, growth fac- 
tors, receptors, chemokines, and neurotransmitter regulators (Düsterhöft et al., 2013, 2014; Schäfer et al., 2017). It is involved in various signal transduction systems of development, reproduction, immunity, inflammatory responses, and carcinogenesis (Black et al., 1997; Blaydon et al., 2011; Düsterhöft et al., 2014).

ADAM17 has been reported to cleave Arg 708 and Ser 709 of ACE2 proximal to the cell membrane, which leaves intact catalytic activity of ACE2 (Lambert et al., 2005) and is responsible for the extracellular shedding of ACE2 (SACE2). The reduction of ADAM17 expression by siRNA results in decreased sACE2, and overexpression of ADAM17 increased sACE2 (Lai et al., 2011; Liu et al., 2020). The physiological role of the extracellular sACE2 activated by ADAM17, particularly during SARS-CoV-2 infection in the heart and lungs through RAS, remains to be determined (Haga et al., 2010).

Given that membrane bound ACE2 plays a receptor function in SARS-CoV-2 infection, it is highly likely that SACE2 affects the pathogenesis of SARS-CoV-2 (Haga et al., 2010; Zipeto et al., 2020). Several studies have suggested that SACE2 could compete with ACE2 only in its binding sites on the S protein (Haga et al., 2010; Lai et al., 2011). Additive recombinant sACE2 in the cell culture system could partially decrease the SARS-CoV infectivity (Jia et al., 2009). On the contrary, when an expression of ADAM17 was inhibited by siRNA, SARSCoV-2 infectivity has decreased overall (Liu et al., 2020). Given these data, the processing of ACE2 and sACE2 interactions involve selective competition associated with the $S$ protein of SARS-CoV-2, and it remains to be identified how the proteolytic function of ADMA17 synergizes or interferes with the viral cell invasion process, which affects viral infectivity (Monteil et al., 2020; Palau et al., 2020). Indeed, cells expressed a mutant form of ACE2, which is resistant to the proteolytic function of ADAM17, and did not show enhancement of SARS-CoV infectivity (Haga et al., 2008, 2010). A pseudovirus-mediated infectivity assay revealed that infectivity was hardly discriminated between normal and ADAM17-resistant mutant ACE2 (Heurich et al., 2014).

These results suggest that the role of SACE2 produced by ADAM17 might have a limited effect on SARS-CoV-2 infection (Haga et al., 2008; Schreiber et al., 2020). Nevertheless, how SACE2 affects the infectivity and pathogenesis of SARSCoV-2 should be further clarified based on the expression rates of ADAM17 in lung tissues and kidneys, both primary entry sites of SARS-CoV-2, which is likely high. The unveiling of potentially hidden links among ADAM17, ACE2, and SACE2 simultaneously presented outside the cell membrane may give insight into the inhibitory mechanism(s) of ACE2 and S protein interactions as a critical determinant of SARS-CoV-2 infectivity.

\section{PROTEINS INVOLVED IN THE ENDOCYTIC PATHWAY}

Depending on the types of viruses, diverse mechanisms are involved in regulating virus entry into the host cells. Cellular proteases, including TMPRSS2, HAT, furin, and trypsin, regulate the viral protein binding to the host cell receptors. These enzymes also play an essential role in the SARSCoV-2 invasion process. However, the functional profile of cellular proteases and the viral infectivity in a particular tissue have not coincided. Many susceptible cell lines to SARS-
CoV-2 express none or a low level of specific proteases that are considered critical for the SARS-CoV-2 cell infection $(\mathrm{Ou}$ et al., 2020; Palau et al., 2020), indicating that the virus can enter the cell in as-yet-found ways, distinctive from proteasemediated entry. In this section, the possibility of SARS-CoV-2 entry by endocytosis, which is protease-independent, will be discussed.

It has been shown that the glycoproteins of various enveloped viruses, such as coronavirus, HIV, or Newcastle disease virus, enter into cells mediated by endocytosis as well as direct membrane fusion (Fackler and Peterlin, 2000; Cantín et al., 2007; Wang et al., 2008; Grimm and Tang, 2020). As a representative example, clathrin-mediated endocytosis machinery has been well studied in the cell entry process of a number of enveloped viruses (Sieczkarski and Whittaker, 2005; Wang et al., 2008). The S protein of SARS-CoV-2 harbors approximately $76 \%$ amino acid sequence identity with SARS-CoV and $\leq 50 \%$ identity with MERS-CoV, which also use cell entry machinery through clathrin-mediated endocytosis after binding to the cell receptor (Sun et al., 2005; Inoue et al., 2007; Yang et al., 2014).

In contrast, HCoV-229E invades fibroblast cells mediated by caveolae, not endocytosis via the clathrin-related-pathway (Nomura, 2005). It employs various methods such as caveolae mediation, flotillin mediation, CLIC/GEECS (CLathrin Independent Carriers/GPI-AP Enriched Endocytic Compartments) mediation micropinocytosis (Gold et al., 2010). It has been shown that macropinocytosis is used when the alveolar pneumocytes of lower respiratory tissues are infected with adenovirus or influenza virus (Glebov, 2020). Interestingly, a report showed that smoking activated macropinocytosis in alveolar epithelial cells (Kälin et al., 2010; de Vries et al., 2011; Qian et al., 2013). More recently, the treatment of macropinocytosis inhibitor ethylisopropylamiloride (EIPA) decreased SARSCoV-2 RNA levels in the cell culture system (Shema Mugisha et al., 2020). Further investigation in association with macropinocytosis as an alternative cell entry pathway and viral pathogenesis remains to be clarified in the context of SARS-CoV-2 infection.

Clathrin-mediated or clathrin-independent endocytosis forms an endosome after the virus enters the cell membrane. Cations such as $\mathrm{Ca}^{2+}$ are introduced through a two-pore channel (TPC) of the endosome, and viral S protein is proteolyzed by cathepsin L/B protease at a low-pH. (Sureda et al., 2020). After the endosomal membranes are fused, viral genes are eventually shed into the cytoplasm (Grimm and Tang, 2020). Therefore, if the life cycle of SARS-CoV-2, which is related to introducing viral particles into the cytoplasm mediated by clathrin, or introducing cations through TPC from the endosome, can be controlled, these could be an additional target for effective therapeutics.

\section{CONCLUSIONS}

The biological characteristics of SARS-CoV-2 need to be thoroughly investigated to fill the gap between scientific knowledge and effective strategies for the diagnosis, treatment, and prevention of this virus. The advent of the furin cleavage site is attributable to the pathogenesis of SAR-CoV-2 differing from previously known HCoVs. Much more details need to be uncovered to understand which proteases are involved in what 
stages of infection and how they contribute to virus infection and transmission to other hosts. Although scientists argue that the furin cleavage site in the S protein of the SARS-CoV-2 is necessary only for cell-cell fusion and not for enhancing viral invasion, other proteases, which are associated with an entire life cycle of the virus, are attractive antiviral targets.

The followings need to be considered: 1) although it has been reported that alternative cell entry machinery exists for both clathrin-mediated and clathrin-independent mechanisms, yet another form of endocytosis apart from the two types of machinery has also been identified; 2) various accessory factors are continuously recognized in protease research; 3) distribution of proteases in the tissue and preferred mechanism vary depending on cellular characteristics, tissue specificity, and viral species.

The successful infection of SARS-CoV-2 requires a series of host cell proteases, and thus functional interference of target molecules is an attractive therapeutic strategy for suppressing virus infection. However, as these enzymes account for intrinsic physiologic functions allocated, interrupting their assigned role by therapeutics likely results in an unwanted consequence. Therefore, therapeutics against the host proteases or other proteins should be carefully designed and monitored.

The COVID-19 pandemic caused by SARS-CoV-2 has posed an enormous challenge to public health, and the threat still has a significant impact on humanity. Although prophylactic vaccines are being licensed and commercialized, repeated global epidemics are expected to continue with measurable cases and fatalities. It appears that social distancing in the public sector is still the primary way to reducing viral transmission. As yet, no prominent therapeutics are approved to managing the devastating clinical outcomes associated with this disease. Moreover, the current understanding of the SARSCoV-2 is limited and has been deduced from the comparison with SARS-CoV, MERS-CoV, and other HCoVs.

Thus, it is clear that further studies are required for the elucidation of viral-host interactions and molecular processes occurring in the cell during and/or after infection to develop an efficient strategy for containment of SARS-CoV-2 infection. Comprehensive progress in understanding biomolecular features linked with clinical practices and immunological characteristics is essential to soothe the current pandemic caused by SARS-CoV-2.

\section{ACKNOWLEDGMENTS}

This research was supported by the Korea Disease Control and Prevention Agency Program, Grant No. 2020ER533000, and from the National Research Foundation of Korea (NRF), funded by the Ministry of Science and ICT, Republic of Korea (Grant No. NRF-2017M3A9E4061995).

\section{REFERENCES}

Alexander, D. J. and Brown, I. H. (2009) History of highly pathogenic avian influenza. Rev. Sci. Tech. 28, 19-38.

Ami, Y., Nagata, N., Shirato, K., Watanabe, R., Iwata, N., Nakagaki, K., Fukushi, S., Saijo, M., Morikawa, S. and Taguchi, F. (2008) Co-infection of respiratory bacterium with severe acute respira- tory syndrome coronavirus induces an exacerbated pneumonia in mice. Microbiol. Immunol. 52, 118-127.

Andersen, K. G., Rambaut, A., Lipkin, W. I., Holmes, E. C. and Garry, R. F. (2020) The proximal origin of SARS-CoV-2. Nat. Med. 26, 450-452.

Baron, J., Tarnow, C., Mayoli-Nüssle, D., Schilling, E., Meyer, D., Hammami, M., Schwalm, F., Steinmetzer, T., Guan, Y., Garten, W., Klenk, H. D. and Böttcher-Friebertshäuser, E. (2013) Matriptase, HAT, and TMPRSS2 activate the hemagglutinin of H9N2 influenza A viruses. J. Virol. 87, 1811-1820.

Bassi, D. E., Zhang, J., Renner, C. and Klein-Szanto, A. J. (2017) Targeting proprotein convertases in furin-rich lung cancer cells results in decreased in vitro and in vivo growth. Mol. Carcinog. 56, 11821188.

Batlle, D., Wysocki, J. and Satchell, K. (2020) Soluble angiotensinconverting enzyme 2: a potential approach for coronavirus infection therapy? Clin. Sci. (Lond.) 134, 543-545.

Belouzard, S., Chu, V. C. and Whittaker, G. R. (2009) Activation of the SARS coronavirus spike protein via sequential proteolytic cleavage at two distinct sites. Proc. Natl. Acad. Sci. U.S.A. 106, 5871-5876.

Belouzard, S., Madu, I. and Whittaker, G. R. (2010) Elastase-mediated activation of the severe acute respiratory syndrome coronavirus spike protein at discrete sites within the S2 domain. J. Biol. Chem. 285, 22758-22763.

Bertram, S., Glowacka, I., Müller, M. A., Lavender, H., Gnirss, K., Nehlmeier, I., Niemeyer, D., He, Y., Simmons, G., Drosten, C., Soilleux, E. J., Jahn, O., Steffen, I. and Pöhlmann, S. (2011) Cleavage and activation of the severe acute respiratory syndrome coronavirus spike protein by human airway trypsin-like protease. J. Virol. $\mathbf{8 5}$, 13363-13372.

Black, R. A., Rauch, C. T., Kozlosky, C. J., Peschon, J. J., Slack, J. L., Wolfson, M. F., Castner, B. J., Stocking, K. L., Reddy, P., Srinivasan, S., Nelson, N., Boiani, N., Schooley, K. A., Gerhart, M., Davis, R., Fitzner, J. N., Johnson, R. S., Paxton, R. J., March, C. J. and Cerretti, D. P. (1997) A metalloproteinase disintegrin that releases tumour-necrosis factor-alpha from cells. Nature 385, 729-733.

Blaydon, D. C., Biancheri, P., Di, W. L., Plagnol, V., Cabral, R. M., Brooke, M. A., van Heel, D. A., Ruschendorf, F., Toynbee, M., Walne, A., O'Toole, E. A., Martin, J. E., Lindley, K., Vulliamy, T., Abrams, D., J., MacDonald, T. T., Harper, J. I. and Kelsell, D. P. (2011) Inflammatory skin and bowel disease linked to ADAM17 deletion. N. Engl. J. Med. 365, 1502-1508.

Bosch, B. J., Bartelink, W. and Rottier, P. J. (2008) Cathepsin L functionally cleaves the severe acute respiratory syndrome coronavirus class I fusion protein upstream of rather than adjacent to the fusion peptide. J. Virol. 82, 8887-8890.

Böttcher-Friebertshäuser, E., Garten, W., Matrosovich, M. and Klenk, H. D. (2014) The hemagglutinin: a determinant of pathogenicity. Curr. Top. Microbiol. Immunol. 385, 3-34.

Buchrieser, J., Dufloo, J., Hubert, M., Monel, B., Planas, D., Rajah, M. M., Planchais, C., Porrot, F., Guivel-Benhassine, F., Van der Werf, S., Casartelli, N., Mouquet, H., Bruel, T. and Schwartz, O. (2020) Syncytia formation by SARS-CoV-2-infected cells. EMBO J. 39, e106267.

Bugge, T. H., Antalis, T. M. and Wu, Q. (2009) Type II transmembrane serine proteases. J. Biol. Chem. 284, 23177-23181.

Cantín, C., Holguera, J., Ferreira, L., Villar, E. and Muñoz-Barroso, I. (2007) Newcastle disease virus may enter cells by caveolae-mediated endocytosis. J. Gen. Virol. 88, 559-569.

Cantuti-Castelvetri, L., Ojha, R., Pedro, L. D., Djannatian, M., Franz, J., Kuivanen, S., van der Meer, F., Kallio, K., Kaya, T., Anastasina, M., Smura, T., Levanov, L., Szirovicza, L., Tobi, A., Kallio-Kokko, H., Österlund, P., Joensuu, M., Meunier, F. A., Butcher, S. J., Winkler, M. S., Mollenhauer, B., Helenius, A., Gokce, O., Teesalu, T., Hepojoki, J., Vapalahti, O., Stadelmann, C., Balistreri, G. and Simons, M. (2020) Neuropilin-1 facilitates SARS-CoV-2 cell entry and infectivity. Science 370, 856-860.

Cheng, Y. W., Chao, T. L., Li, C. L., Chiu, M. F., Kao, H. C., Wang, S. H., Pang, Y. H., Lin, C. H., Tsai, Y. M., Lee, W. H., Tao, M. H., Ho, T. C., Wu, P. Y., Jang, L. T., Chen, P. J., Chang, S. Y. and Yeh, S. H. (2020) Furin inhibitors block SARS-CoV-2 spike protein cleavage to suppress virus production and cytopathic effects. Cell Rep. 
33, 108254

Coronaviridae Study Group of the International Committee on Taxonomy of Viruses (2020) The species Severe acute respiratory syndrome-related coronavirus: classifying 2019-nCoV and naming it SARS-CoV-2. Nat. Microbiol. 5, 536-544.

Coutard, B., Valle, C., de Lamballerie, X., Canard, B., Seidah, N. G. and Decroly, E. (2020) The spike glycoprotein of the new coronavirus 2019-nCoV contains a furin-like cleavage site absent in CoV of the same clade. Antiviral Res. 176, 104742.

Daly, J. L., Simonetti, B., Klein, K., Chen, K. E., Williamson, M. K., Antón-Plágaro, C., Shoemark, D. K., Simón-Gracia, L., Bauer, M., Hollandi, R., Greber, U. F., Horvath, P., Sessions, R. B., Helenius, A., Hiscox, J. A., Teesalu, T., Matthews, D. A., Davidson, A. D., Collins, B. M., Cullen, P. J. and Yamauchi, Y. (2020) Neuropilin-1 is a host factor for SARS-CoV-2 infection. Science 370, 861-865

Danser, A. H. J., Epstein, M. and Batlle, D. (2020) Renin-angiotensin system blockers and the COVID-19 pandemic: at present there is no evidence to abandon renin-angiotensin system blockers. $\mathrm{Hy}$ pertension 75, 1382-1385.

Das, S., Ravi, V. and Desai, A. (2011) Japanese encephalitis virus interacts with vimentin to facilitate its entry into porcine kidney cell line. Virus Res. 160, 404-408.

de Vries, E., Tscherne, D. M., Wienholts, M. J., Cobos-Jiménez, V., Scholte, F., García-Sastre, A., Rottier, P. J. and de Haan, C. A (2011) Dissection of the influenza A virus endocytic routes reveals macropinocytosis as an alternative entry pathway. PLoS Pathog. 7, e1001329.

Delmas, B., Gelfi, J., L'Haridon, R., Vogel, L. K., Sjöström, H., Norén, O. and Laude, H. (1992) Aminopeptidase $\mathrm{N}$ is a major receptor for the entero-pathogenic coronavirus TGEV. Nature 357, 417-420

Denison, M. R., Graham, R. L., Donaldson, E. F., Eckerle, L. D. and Baric, R. S. (2011) Coronaviruses: an RNA proofreading machine regulates replication fidelity and diversity. RNA Biol. 8, 270-279.

Ding, Y., Wang, H., Shen, H., Li, Z., Geng, J., Han, H., Cai, J., Li, X., Kang, W., Weng, D., Lu, Y., Wu, D., He, L. and Yao, K. (2003) The clinical pathology of severe acute respiratory syndrome (SARS): a report from China. J. Pathol. 200, 282-289.

Donoghue, M., Hsieh, F., Baronas, E., Godbout, K., Gosselin, M., Stagliano, N., Donovan, M., Woolf, B., Robison, K., Jeyaseelan, R. Breitbart, R. E. and Acton, S. (2000) A novel angiotensin-converting enzyme-related carboxypeptidase (ACE2) converts angiotensin I to angiotensin 1-9. Circ. Res. 87, E1-E9.

Drees, L., Königsmann, T., Jaspers, M., Pflanz, R., Riedel, D. and Schuh, R. (2019) Conserved function of the matriptase-prostasin proteolytic cascade during epithelial morphogenesis. PLoS Genet. 15, e1007882.

Düsterhöft, S., Höbel, K., Oldefest, M., Lokau, J., Waetzig, G. H., Chalaris, A., Garbers, C., Scheller, J., Rose-John, S., Lorenzen, I. and Grötzinger, J. (2014) A disintegrin and metalloprotease 17 dynamic interaction sequence, the sweet tooth for the human interleukin 6 receptor. J. Biol. Chem. 289, 16336-16348.

Düsterhöft, S., Jung, S., Hung, C. W., Tholey, A., Sönnichsen, F. D., Grötzinger, J. and Lorenzen, I. (2013) Membrane-proximal domain of a disintegrin and metalloprotease- 17 represents the putative molecular switch of its shedding activity operated by protein-disulfide isomerase. J. Am. Chem. Soc. 135, 5776-5781.

Fackler, O. T. and Peterlin, B. M. (2000) Endocytic entry of HIV-1. Curr. Biol. 10, 1005-1008.

Ferrario, C. M., Jessup, J., Chappell, M. C., Averill, D. B., Brosnihan, K. B., Tallant, E. A., Diz, D. I. and Gallagher, P. E. (2005) Effect of angiotensin-converting enzyme inhibition and angiotensin II receptor blockers on cardiac angiotensin-converting enzyme 2. Circulation 111, 2605-2610.

Glebov, O. O. (2020) Understanding SARS-CoV-2 endocytosis for COVID-19 drug repurposing. FEBS J. 287, 3664-3671.

Glowacka, I., Bertram, S., Müller, M. A., Allen, P., Soilleux, E., Pfefferle, S., Steffen, I., Tsegaye, T. S., He, Y., Gnirss, K., Niemeyer, D., Schneider, H., Drosten, C. and Pöhlmann, S. (2011) Evidence that TMPRSS2 activates the severe acute respiratory syndrome coronavirus spike protein for membrane fusion and reduces vira control by the humoral immune response. J. Virol. 85, 4122-4134.

Gold, S., Monaghan, P., Mertens, P. and Jackson, T. (2010) A clathrin independent macropinocytosis-like entry mechanism used by bluetongue virus-1 during infection of BHK cells. PLOS ONE 5, e11360.

Gomes, C. P., Fernandes, D. E., Casimiro, F., da Mata, G. F., Passos, M. T., Varela, P., Mastroianni-Kirsztajn, G. and Pesquero, J. B. (2020) Cathepsin L in COVID-19: from pharmacological evidences to genetics. Front. Cell. Infect. Microbiol. 10, 589505.

Grimm, C. and Tang, R. (2020) Could an endo-lysosomal ion channel be the Achilles heel of SARS-CoV2? Cell Calcium 88, 102212.

Haga, S., Nagata, N., Okamura, T., Yamamoto, N., Sata, T., Yamamoto, N., Sasazuki, T. and Ishizaka, Y. (2010) TACE antagonists blocking ACE2 shedding caused by the spike protein of SARS-CoV are candidate antiviral compounds. Antiviral Res. 85, 551-555.

Haga, S., Yamamoto, N., Nakai-Murakami, C., Osawa, Y., Tokunaga, K., Sata, T., Yamamoto, N., Sasazuki, T. and Ishizaka, Y. (2008) Modulation of TNF-alpha-converting enzyme by the spike protein of SARS-CoV and ACE2 induces TNF-alpha production and facilitates viral entry. Proc. Natl. Acad. Sci. U.S.A. 105, 7809-7814.

Hamilton, B. S., Gludish, D. W. and Whittaker, G. R. (2012) Cleavage activation of the human-adapted influenza virus subtypes by matriptase reveals both subtype and strain specificities. J. Virol. 86, 10579-10586.

Hamming, I., Timens, W., Bulthuis, M. L., Lely, A. T., Navis, G. and van Goor, H. (2004) Tissue distribution of ACE2 protein, the functional receptor for SARS coronavirus. A first step in understanding SARS pathogenesis. J. Pathol. 203, 631-637.

Heurich, A., Hofmann-Winkler, H., Gierer, S., Liepold, T., Jahn, O. and Pöhlmann, S. (2014) TMPRSS2 and ADAM17 cleave ACE2 differentially and only proteolysis by TMPRSS2 augments entry driven by the severe acute respiratory syndrome coronavirus spike protein. J. Virol. 88, 1293-1307.

Hoffmann, H. H., Schneider, W. M., Blomen, V. A., Scull, M. A., Hovnanian, A., Brummelkamp, T. R. and Rice, C. M. (2017) Diverse viruses require the calcium transporter SPCA1 for maturation and spread. Cell Host Microbe 22, 460-470.e5.

Hoffmann, M., Hofmann-Winkler, H., Smith, J. C., Krüger, N., Arora, P., Sørensen, L. K., Søgaard, O. S., Hasselstrøm, J. B., Winkler, M., Hempel, T., Raich, L., Olsson, S., Danov, O., Jonigk, D., Yamazoe, T., Yamatsuta, K., Mizuno, H., Ludwig, S., Noé, F., Kjolby, M., Braun, A., Sheltzer, J. M. and Pöhlmann, S. (2021) Camostat mesylate inhibits SARS-CoV-2 activation by TMPRSS2-related proteases and its metabolite GBPA exerts antiviral activity. EBioMedicine 65, 103255

Hoffmann, M., Kleine-Weber, H. and Pöhlmann, S. (2020a) A multibasic cleavage site in the spike protein of SARS-CoV-2 is essential for infection of human lung cells. Mol. Cell 78, 779-784.e5.

Hoffmann, M., Kleine-Weber, H., Schroeder, S., Krüger, N., Herrler, T., Erichsen, S., Schiergens, T. S., Herrler, G., Wu, N. H., Nitsche, A., Müller, M. A., Drosten, C. and Pöhlmann, S. (2020b) SARS-CoV-2 cell entry depends on ACE2 and TMPRSS2 and is blocked by a clinically proven protease inhibitor. Cell 181, 271-280.e8.

Hussain, M., Jabeen, N., Raza, F., Shabbir, S., Baig, A. A., Amanullah, A. and Aziz, B. (2020) Structural variations in human ACE2 may influence its binding with SARS-CoV-2 spike protein. J. Med. Virol. 92, 1580-1586.

Huynh, T., Wang, H. and Luan, B. (2020) In silico exploration of the molecular mechanism of clinically oriented drugs for possibly inhibiting SARS-CoV-2's main protease. J. Phys. Chem. Lett. 11, 4413-4420.

Inoue, Y., Tanaka, N., Tanaka, Y., Inoue, S., Morita, K., Zhuang, M., Hattori, T. and Sugamura, K. (2007) Clathrin-dependent entry of severe acute respiratory syndrome coronavirus into target cells expressing ACE2 with the cytoplasmic tail deleted. J. Virol. 81, 8722-8729.

Jarvis, A., Allerston, C. K., Jia, H., Herzog, B., Garza-Garcia, A., Winfield, N., Ellard, K., Aqil, R., Lynch, R., Chapman, C., Hartzoulakis, B., Nally, J., Stewart, M., Cheng, L., Menon, M., Tickner, M., Djordjevic, S., Driscoll, P. C., Zachary, I. and Selwood, D. L. (2010) Small molecule inhibitors of the neuropilin-1 vascular endothelial growth factor A (VEGF-A) interaction. J. Med. Chem. 53, 2215-2226.

Jia, H. P., Look, D. C., Tan, P., Shi, L., Hickey, M., Gakhar, L., Chappell, M. C., Wohlford-Lenane, C. and McCray, P. B., Jr. (2009) Ectodomain shedding of angiotensin converting enzyme 2 in hu- 
man airway epithelia. Am. J. Physiol. Lung Cell. Mol. Physiol. 297, L84-L96.

Kälin, S., Amstutz, B., Gastaldelli, M., Wolfrum, N., Boucke, K., Havenga, M., DiGennaro, F., Liska, N., Hemmi, S. and Greber, U. F. (2010) Macropinocytotic uptake and infection of human epithelial cells with species B2 adenovirus type 35. J. Virol. 84, 5336-5350.

Kam, Y. W., Okumura, Y., Kido, H., Ng, L. F., Bruzzone, R. and Altmeyer, R. (2009) Cleavage of the SARS coronavirus spike glycoprotein by airway proteases enhances virus entry into human bronchial epithelial cells in vitro. PLOS ONE 4, e7870.

Kato, M., Hashimoto, T., Shimomura, T., Kataoka, H., Ohi, H. and Kitamura, N. (2012) Hepatocyte growth factor activator inhibitor type 1 inhibits protease activity and proteolytic activation of human airway trypsin-like protease. J. Biochem. 151, 179-187.

Kawabata, K., Hagio, T. and Matsuoka, S. (2002) The role of neutrophil elastase in acute lung injury. Eur. J. Pharmacol. 451, 1-10.

Kim, J. K., Fahad, A. M., Shanmukhappa, K. and Kapil, S. (2006) Defining the cellular target(s) of porcine reproductive and respiratory syndrome virus blocking monoclonal antibody 7G10. J. Virol. 80, 689-696.

Kleine-Weber, H., Elzayat, M. T., Hoffmann, M. and Pöhlmann, S. (2018) Functional analysis of potentiall cleavage sites in the MERS-coronavirus spike protein. Sci. Rep. 8, 16597.

Korkmaz, B., Lesner, A., Marchand-Adam, S., Moss, C. and Jenne, D. E. (2020) Lung protection by cathepsin C inhibition: a new hope for COVID-19 and ARDS? J. Med. Chem. 63, 13258-13265.

Koudelka, K. J., Destito, G., Plummer, E. M., Trauger, S. A., Siuzdak, G. and Manchester, M. (2009) Endothelial targeting of cowpea mosaic virus (CPMV) via surface vimentin. PLoS Pathog. 5, e1000417.

Kuba, K., Imai, Y. and Penninger, J. M. (2006) Angiotensin-converting enzyme 2 in lung diseases. Curr. Opin. Pharmacol. 6, 271-276.

Lai, Z. W., Hanchapola, I., Steer, D. L. and Smith, A. I. (2011) Angiotensin-converting enzyme 2 ectodomain shedding cleavagesite identification: determinants and constraints. Biochemistry $\mathbf{5 0}$, 5182-5194.

Lambert, D. W., Yarski, M., Warner, F. J., Thornhill, P., Parkin, E. T., Smith, A. I., Hooper, N. M. and Turner, A. J. (2005) Tumor necrosis factor-alpha convertase (ADAM17) mediates regulated ectodomain shedding of the severe-acute respiratory syndrome-coronavirus (SARS-CoV) receptor, angiotensin-converting enzyme-2 (ACE2). J. Biol. Chem. 280, 30113-30119.

Lan, J., Ge, J., Yu, J., Shan, S., Zhou, H., Fan, S., Zhang, Q., Shi, X., Wang, Q., Zhang, L. and Wang, X. (2020) Structure of the SARSCoV-2 spike receptor-binding domain bound to the ACE2 receptor. Nature 581, 215-220.

Le Coupanec, A., Desforges, M., Meessen-Pinard, M., Dubé, M., Day, R., Seidah, N. G. and Talbot, P. J. (2015) Cleavage of a neuroinvasive human respiratory virus spike glycoprotein by proprotein convertases modulates neurovirulence and virus spread within the central nervous system. PLoS Pathog. 11, e1005261.

$\mathrm{Li}, \mathrm{F}$. (2016) Structure, function, and evolution of coronavirus spike proteins. Annu. Rev. Virol. 3, 237-261.

Li, F., Berardi, M., Li, W., Farzan, M., Dormitzer, P. R. and Harrison, S. C. (2006) Conformational states of the severe acute respiratory syndrome coronavirus spike protein ectodomain. J. Virol. 80, 6794-6800.

Li, M. Y., Li, L., Zhang, Y. and Wang, X. S. (2020) Expression of the SARS-CoV-2 cell receptor gene ACE2 in a wide variety of human tissues. Infect. Dis. Poverty 9, 45.

Li, W., Moore, M. J., Vasilieva, N., Sui, J., Wong, S. K., Berne, M. A., Somasundaran, M., Sullivan, J. L., Luzuriaga, K., Greenough, T. C., Choe, H. and Farzan, M. (2003) Angiotensin-converting enzyme 2 is a functional receptor for the SARS coronavirus. Nature 426, 450-454

List, K., Bugge, T. H. and Szabo, R. (2006) Matriptase: potent proteolysis on the cell surface. Mol. Med. 12, 1-7.

Liu, P. P., Blet, A., Smyth, D. and Li, H. (2020) The science underlying COVID-19: implications for the cardiovascular system. Circulation 142, 68-78.

Lu, G., Hu, Y., Wang, Q., Qi, J., Gao, F., Li, Y., Zhang, Y., Zhang, W., Yuan, Y., Bao, J., Zhang, B., Shi, Y., Yan, J. and Gao, G. F. (2013)
Molecular basis of binding between novel human coronavirus MERS-CoV and its receptor CD26. Nature 500, 227-231.

Luczo, J. M., Stambas, J., Durr, P. A., Michalski, W. P. and Bingham, J. (2015) Molecular pathogenesis of H5 highly pathogenic avian influenza: the role of the haemagglutinin cleavage site motif. Rev. Med. Virol. 25, 406-430.

Matsushima, R., Takahashi, A., Nakaya, Y., Maezawa, H., Miki, M., Nakamura, Y., Ohgushi, F. and Yasuoka, S. (2006) Human airway trypsin-like protease stimulates human bronchial fibroblast proliferation in a protease-activated receptor-2-dependent pathway. Am. J. Physiol. Lung Cell. Mol. Physiol. 290, L385- L395.

Matsuyama, S. (2011) Protease-dependent cell entry mechanism of coronaviruses. Uirusu 61, 109-116.

Matsuyama, S., Nagata, N., Shirato, K., Kawase, M., Takeda, M. and Taguchi, F. (2010) Efficient activation of the severe acute respiratory syndrome coronavirus spike protein by the transmembrane protease TMPRSS2. J. Virol. 84, 12658-12664.

Matsuyama, S., Nao, N., Shirato, K., Kawase, M., Saito, S., Takayama, I., Nagata, N., Sekizuka, T., Katoh, H., Kato, F., Sakata, M., Tahara, M., Kutsuna, S., Ohmagari, N., Kuroda, M., Suzuki, T., Kageyama, T. and Takeda, M. (2020) Enhanced isolation of SARS-CoV-2 by TMPRSS2-expressing cells. Proc. Natl. Acad. Sci. U.S.A. 117, 7001-7003.

Matsuyama, S., Ujike, M., Morikawa, S., Tashiro, M. and Taguchi, F. (2005) Protease-mediated enhancement of severe acute respiratory syndrome coronavirus infection. Proc. Natl. Acad. Sci. U.S.A. 102, 12543-12547.

Mbikay, M., Sirois, F., Yao, J., Seidah, N. G. and Chrétien, M. (1997) Comparative analysis of expression of the proprotein convertases furin, PACE4, PC1 and PC2 in human lung tumours. Br. J. Cancer 75, 1509-1514.

Menachery, V. D., Dinnon, K. H., 3rd, Yount, B. L., Jr., McAnarney, E. T., Gralinski, L. E., Hale, A., Graham, R. L., Scobey, T., Anthony, S. J., Wang, L., Graham, B., Randell, S. H., Lipkin, W. I. and Baric, R. S. (2020) Trypsin treatment unlocks barrier for zoonotic bat coronavirus infection. J. Virol. 94, e01774-19.

Millet, J. K. and Whittaker G. R. (2015) Host cell proteases: critical determinants of coronavirus tropism and pathogenesis. Virus Res. 202, 120-134.

Millet, J. K. and Whittaker, G. R. (2014) Host cell entry of Middle East respiratory syndrome coronavirus after two-step, furin-mediated activation of the spike protein. Proc. Natl. Acad. Sci. U.S.A. 111, 15214-15219.

Mizuiri, S. and Ohashi, Y. (2015) ACE and ACE2 in kidney disease. World J. Nephrol. 4, 74-82.

Monteil, V., Kwon, H., Prado, P., Hagelkrüys, A., Wimmer, R. A., Stahl, M., Leopoldi, A., Garreta, E., Hurtado Del Pozo, C., Prosper, F., Romero, J. P., Wirnsberger, G., Zhang, H., Slutsky, A. S., Conder, R., Montserrat, N., Mirazimi, A. and Penninger, J. M. (2020) Inhibition of SARS-CoV-2 infections in engineered human tissues using clinical-grade soluble human ACE2. Cell 181, 905-913.e7.

Mor-Vaknin, N., Punturieri, A., Sitwala, K. and Markovitz, D. M. (2003) Vimentin is secreted by activated macrophages. Nat. Cell Biol. 5, 59-63.

Munster, V. J., Schrauwen, E. J., de Wit, E., van den Brand, J. M., Bestebroer, T. M., Herfst, S., Rimmelzwaan, G. F., Osterhaus, A. D. and Fouchier, R. A. (2010) Insertion of a multi-basic cleavage motif into the hemagglutinin of a low-pathogenic avian influenza H6N1 virus induces a highly pathogenic phenotype. J. Virol. 84, 7953-7960.

Murza, A., Dion, S. P., Boudreault, P. L., Désilets, A., Leduc, R. and Marsault, É. (2020) Inhibitors of type II transmembrane serine proteases in the treatment of diseases of the respiratory tract - a review of patent literature. Expert Opin. Ther. Pat. 30, 807-824.

Mwenda, M., Saasa, N., Sinyange, N., Busby., G., Chipimo, P. J., Hendry, J., Kapona, O., Yingst, S., Hines, J. Z., Minchella, P., Simulundu, E., Changula, K., Nalubamba, K. S., Sawa, H., Kajihara, M., Yamagishi, J., Kapin'a, M., Kapata, N., Fwoloshi, S., Zulu, P., Mulenga, L. B., Agolory, S., Mukonka, V. and Bridges, D. J. (2020) Detection of B.1.351 SARS-CoV-2 variant strain - Zambia, December 2020. MMWR Morb. Mortal. Wkly. Rep. 70, 280-282.

Nakayama, K. (1997) Furin: a mammalian subtilisin/Kex2p-like endo- 
protease involved in processing of a wide variety of precursor proteins. Biochem. J. 327, 625-635.

Nedelkov, D. (2008) Population proteomics: investigation of protein diversity in human populations. Proteomics 8, 779-786.

Nomura, R. (2005) Caveolar endocytosis and virus entry. Uirusu 55, 19-26.

Ou, X., Liu, Y., Lei, X., Li, P., Mi, D., Ren, L., Guo, L., Guo, R., Chen, T. Hu, J., Xiang, Z., Mu, Z., Chen, X., Chen, J., Hu, K., Jin, Q., Wang, J. and Qian, Z. (2020) Characterization of spike glycoprotein of SARS-CoV-2 on virus entry and its immune cross-reactivity with SARS-CoV. Nat. Commun. 11, 1620.

Palau, V., Riera, M. and Soler, M. J. (2020) ADAM17 inhibition may exert a protective effect on COVID-19. Nephrol. Dial. Transplant. 35, 1071-1072.

Perico, L., Benigni, A. and Remuzzi, G. (2020) Should COVID-19 concern nephrologists? Why and to what extent? The emerging impasse of angiotensin blockade. Nephron 144, 213-221.

Qian, Z., Dominguez, S. R. and Holmes, K. V. (2013) Role of the spike glycoprotein of human Middle East respiratory syndrome coronavirus (MERS-CoV) in virus entry and syncytia formation. PLOS ONE 8, e76469.

Ramos, I., Stamatakis, K., Oeste, C. L. and Pérez-Sala, D. (2020) Vimentin as a multifaceted player and potential therapeutic target in viral infections. Int. J. Mol. Sci. 21, 4675.

Roth, L., Prahst, C., Ruckdeschel, T., Savant, S., Weström, S., Fantin, A., Riedel, M., Héroult, M., Ruhrberg, C. and Augustin, H. G. (2016) Neuropilin-1 mediates vascular permeability independently of vascular endothelial growth factor receptor-2 activation. Sci. Signal. 9, ra42.

Sahebnasagh, A., Saghafi, F., Safdari, M., Khataminia, M., Sadremomtaz, A., Talaei, Z., RezaiGhaleno, H., Bagheri, M., Habtemariam, S. and Avan, R. (2020) Neutrophil elastase inhibitor (sivelestat) may be a promising therapeutic option for management of acute lung injury/acute respiratory distress syndrome or disseminated intravascular coagulation in COVID-19. J. Clin. Pharm. Ther. 45, 1515-1519.

Sales, K. U., Hobson, J. P., Wagenaar-Miller, R., Szabo, R., Rasmussen, A. L., Bey, A., Shah, M. F., Molinolo, A. A. and Bugge, T. H. (2011) Expression and genetic loss of function analysis of the HAT/ DESC cluster proteases TMPRSS11A and HAT. PLoS ONE 6, e23261.

Schäfer, G., Graham, L. M., Lang, D. M., Blumenthal, M. J., Bergant Marušič, M. and Katz, A. A. (2017) Vimentin modulates infectious internalization of human papillomavirus 16 pseudovirions. J. Virol. 91, e00307-17.

Scheibner, D., Ulrich, R., Fatola, O. I., Graaf, A., Gischke, M., Salaheldin, A. H., Harder, T. C., Veits, J., Mettenleiter, T. C. and Abdelwhab, E. M. (2019) Variable impact of the hemagglutinin polybasic cleavage site on virulence and pathogenesis of avian influenza H7N7 virus in chickens, turkeys and ducks. Sci. Rep. 9, 11556.

Schreiber, B., Patel, A. and Verma, A. (2020) Shedding light on COVID-19: ADAM17 the missing link? Am. J. Ther. doi: 10.1097/ MJT.0000000000001226 [Online ahead of print].

Seidah, N. G. and Prat, A. (2012) The biology and therapeutic targeting of the proprotein convertases. Nat. Rev. Drug Discov. 11, 367-383.

Seidah, N. G., and Chrétien, M. (1999) Proprotein and prohormone convertases: a family of subtilases generating diverse bioactive polypeptides. Brain Res. 848, 45-62.

Shang, J., Ye, G., Shi, K., Wan, Y., Luo, C., Aihara, H., Geng, Q., Auerbach, A. and Li, F. (2020a) Structural basis of receptor recognition by SARS-CoV-2. Nature 581, 221-224.

Shang, J., Wan, Y., Luo, C., Ye, G., Geng, Q., Auerbach, A. and Li, F. (2020b) Cell entry mechanisms of SARS-CoV-2. Proc. Natl. Acad. Sci. U.S.A. 117, 11727-11734.

Shema Mugisha, C., Vuong, H. R., Puray-Chavez, M., Bailey, A. L. Fox, J. M., Chen, R. E., Wessel, A. W., Scott, J. M., Harastani, H. H., Boon, A., Shin, H. and Kutluay, S. B. (2020) A simplified quantitative real-time PCR assay for monitoring SARS-CoV-2 growth in cell culture. mSphere 5, e00658-20.

Shi, J. Y., Pan, H. Y., Liu, K., Pan, M. and Si, G. J. (2020) Expression of ectopic trypsin in atherosclerotic plaques and the effects of aprotinin on plaque stability. Arch. Biochem. Biophys. 690, 108460.

Shirato, K., Kawase, M. and Matsuyama, S. (2013) Middle East respiratory syndrome coronavirus infection mediated by the transmembrane serine protease TMPRSS2. J. Virol. 87, 12552-12561.

Shrimp, J. H., Kales, S. C., Sanderson, P. E., Simeonov, A., Shen, M. and Hall, M. D. (2020) An enzymatic TMPRSS2 assay for assessment of clinical candidates and discovery of inhibitors as potential treatment of COVID-19. ACS Pharmacol. Transl. Sci. 3, 997-1007

Shulla, A., Heald-Sargent, T., Subramanya, G., Zhao, J., Perlman, S. and Gallagher, T. (2011) A transmembrane serine protease is linked to the severe acute respiratory syndrome coronavirus receptor and activates virus entry. J. Virol. 85, 873-882.

Sieczkarski, S. B. and Whittaker, G. R. (2005) Characterization of the host cell entry of filamentous influenza virus. Arch. Virol. 150, 1783-1796.

South, A. M., Tomlinson, L., Edmonston, D., Hiremath, S. and Sparks, M. A. (2020) Controversies of renin-angiotensin system inhibition during the COVID-19 pandemic. Nat. Rev. Nephrol. 16, 305-307.

Stip, E., Rizvi, T. A., Mustafa, F., Javaid, S., Aburuz, S., Ahmed, N. N., Abdel Aziz, K., Arnone, D., Subbarayan, A., Al Mugaddam, F. and Khan, G. (2020) The large action of chlorpromazine: translational and transdisciplinary considerations in the face of COVID-19. Front. Pharmacol. 11, 577678.

Suguitan, A. L., Jr., Matsuoka, Y., Lau, Y. F., Santos, C. P., Vogel, L., Cheng, L. I., Orandle, M. and Subbarao, K. (2012) The multi-basic cleavage site of the hemagglutinin of highly pathogenic A/Vietnam/1203/2004 (H5N1) avian influenza virus acts as a virulence factor in a host-specific manner in mammals. J. Virol. 86, 27062714.

Sun, X., Yau, V. K., Briggs, B. J. and Whittaker, G. R. (2005) Role of clathrin-mediated endocytosis during vesicular stomatitis virus entry into host cells. Virology $338,53-60$.

Sureda, A., Alizadeh, J., Nabavi, S. F., Berindan-Neagoe, I., Cismaru, C. A., Jeandet, P., Łos, M. J., Clementi, E., Nabavi, S. M. and Ghavami, S. (2020) Endoplasmic reticulum as a potential therapeutic target for covid-19 infection management? Eur. J. Pharmacol. 882, 173288.

Tada, T., Dcosta, B. M., Samanovic-Golden, M., Herati, R. S., Cornelius, A., Mulligan, M. J. and Landau, N. R. (2021) Neutralization of viruses with European, South African, and United States SARS-CoV-2 variant spike proteins by convalescent sera and BNT162b2 mRNA vaccine-elicited antibodies. bioRxiv doi: 10.1101/2021.02.05.430003 [Preprint].

Teesalu, T., Sugahara, K. N., Kotamraju, V. R. and Ruoslahti, E. (2009) C-end rule peptides mediate neuropilin-1-dependent cell, vascular, and tissue penetration. Proc. Natl. Acad. Sci. U.S.A. 106, 1615716162.

Thomas, G. (2002) Furin at the cutting edge: from protein traffic to embryogenesis and disease. Nat. Rev. Mol. Cell Biol. 3, 753-766.

Thul, P. J., Åkesson, L., Wiking, M., Mahdessian, D., Geladaki, A., AitBlal, H., Alm, T., Asplund, A., Björk, L., Breckels, L. M., Bäckström, A., Danielsson, F., Fagerberg, L., Fall, J., Gatto, L., Gnann, C., Hober, S., Hjelmare, M., Johansson, F., Lee, S., Lindskog, C., Mulder, J., Mulvey, C. M., Nilsson, P., Oksvold, P., Rockberg, J., Schutten, R., Schwenk, J. M., Sivertsson, Å., Sjöstedt, E., Skogs, M., Stadler, C., Sullivan, D. P., Tegel, H., Winsnes, C., Zhang, C., Zwahlen, M., Mardinoglu, A., Pontén, F., von Feilitzen, K., Lilley, K. S., Uhlén, M. and Lundberg, E. (2017) A subcellular map of the human proteome. Science 356, eaal3321.

Tian, F., Tong, B., Sun, L., Shi, S., Zheng, B., Wang, Z., Dong, X. and Zheng, P. (2021) Mutation N501Y in RBD of spike protein strengthens the interaction between COVID-19 and its receptor ACE2. bioRxiv doi: 10.1101/2021.02.14.431117 [Preprint].

To, K. F. and Lo, A. W. (2004) Exploring the pathogenesis of severe acute respiratory syndrome (SARS): the tissue distribution of the coronavirus (SARS-CoV) and its putative receptor, angiotensinconverting enzyme 2 (ACE2). J. Pathol. 203, 740-743.

Vijay, R. (2020) MERS Coronavirus Methods and Protocols. Part of the Methods in Molecular Biology book series. pp. 21-37. Springer.

Walls, A. C., Park, Y. J., Tortorici, M. A., Wall, A., McGuire, A. T. and Veesler, D. (2020) Structure, function, and antigenicity of the SARS-CoV-2 spike glycoprotein. Cell 181, 281-292. 
Wang, H., Yang, P., Liu, K., Guo, F., Zhang, Y., Zhang, G. and Jiang C. (2008) SARS coronavirus entry into host cells through a nove clathrin- and caveolae-independent endocytic pathway. Cell Res. 18, 290-301.

Wang, Q., Qiu, Y., Li, J. Y., Zhou, Z. J., Liao, C. H. and Ge, X. Y. (2020a) A unique protease cleavage site predicted in the spike protein of the novel pneumonia coronavirus (2019-nCoV) potentially related to viral transmissibility. Virol. Sin. 35, 337-339.

Wang, Q., Zhang, Y., Wu, L., Niu, S., Song, C., Zhang, Z., Lu, G., Qiao, C., Hu, Y., Yuen, K. Y., Wang, Q., Zhou, H., Yan, J. and Qi J. (2020b) Structural and functional basis of SARS-CoV-2 entry by using human ACE2. Cell 181, 894-904.

Wibmer, C. K., Ayres, F., Hermanus, T., Madzivhandila, M., Kgagudi, P., Oosthuysen, B., Lambson, B. E., de Oliveira, T., Vermeulen, M., van der Berg, K., Rossouw, T., Boswell, M., Ueckermann, V., Meiring, S., von Gottberg, A., Cohen, C., Morris, L., Bhiman, J. N. and Moore, P. L. (2021) SARS-CoV-2 501Y.V2 escapes neutralization by South African COVID-19 donor plasma. Nat. Med. doi: 10.1038/ s41591-021-01285-x [Online ahead of print].

Worldometers.info (2021) Coronavirus Update. Available from: https:// www.worldometers.info/coronavirus/ [accessed 2021 Mar 25].

Wrapp, D., Wang, N., Corbett, K. S., Goldsmith, J. A., Hsieh, C. L., Abiona, O., Graham, B. S. and McLellan, J. S. (2020) Cryo-EM structure of the 2019-nCoV spike in the prefusion conformation. Science 367, 1260-1263.

Wu, F., Zhao, S., Yu, B., Chen, Y. M., Wang, W., Song, Z. G., Hu, Y., Tao, Z. W., Tian, J. H., Pei, Y. Y., Yuan, M. L., Zhang, Y. L., Dai, F. H., Liu, Y., Wang, Q. M., Zheng, J. J., Xu, L., Holmes, E. C. and Zhang, Y. Z. (2020) A new coronavirus associated with human respiratory disease in China. Nature 579, 265-269.

Wu, J., Deng, W., Li, S. and Yang, X. (2021) Advances in research on ACE2 as a receptor for 2019-nCoV. Cell. Mol. Life Sci. 78, 531544

Wysocki, J., Ye, M., Rodriguez, E., González-Pacheco, F. R., Barrios, C., Evora, K., Schuster, M., Loibner, H., Brosnihan, K., B., Ferrario, C. M., Penninger, J. M. and Batlle, D. (2010) Targeting the degradation of angiotensin II with recombinant angiotensinconverting enzyme 2: prevention of angiotensin II-dependent hypertension. Hypertension 55, 90-98.

Xia, S., Liu, M., Wang, C., Xu, W., Lan, Q., Feng, S., Qi, F., Bao, L., Du, L., Liu, S., Qin, C., Sun, F., Shi, Z., Zhu, Y., Jiang, S. and Lu, L. (2020) Inhibition of SARS-CoV-2 (previously 2019-nCoV) infection by a highly potent pan-coronavirus fusion inhibitor targeting its spike protein that harbors a high capacity to mediate membrane fusion. Cell Res. 30, 343-355.

Yan, R., Zhang, Y., Li, Y., Xia, L., Guo, Y. and Zhou, Q. (2020) Structural basis for the recognition of SARS-CoV-2 by full-length human ACE2. Science 367, 1444-1448.

Yang, Y., Du, L., Liu, C., Wang, L., Ma, C., Tang, J., Baric, R. S., Jiang S. and Li, F. (2014) Receptor usage and cell entry of bat coronavirus HKU4 provide insight into bat-to-human transmission of MERS coronavirus. Proc. Natl. Acad. Sci. U.S.A. 111, 12516-12521.

Yao, Y. X., Ren, J., Heinen, P., Zambon, M. and Jones, I. M. (2004) Cleavage and serum reactivity of the severe acute respiratory syndrome coronavirus spike protein. J. Infect. Dis. 190, 91-98.

Yasuoka, S., Ohnishi, T., Kawano, S., Tsuchihashi, S., Ogawara, M., Masuda, K., Yamaoka, K., Takahashi, M. and Sano, T. (1997) Purification, characterization, and localization of a novel trypsin-like protease found in the human airway. Am. J. Respir. Cell Mol. Biol. 16, 300-308.

Yeager, C. L., Ashmun, R. A., Williams, R. K., Cardellichio, C. B., Shapiro, L. H., Look, A. T. and Holmes, K. V. (1992) Human aminopeptidase $\mathrm{N}$ is a receptor for human coronavirus 229E. Nature 357 , 420-422.

Yu, Y. T., Chien, S. C., Chen, I. Y., Lai, C. T., Tsay, Y. G., Chang, S. C., and Chang, M. F. (2016) Surface vimentin is critical for the cell entry of SARS-CoV. J. Biomed. Sci. 23, 14.

Yuan, Y., Cao, D., Zhang, Y., Ma, J., Qi, J., Wang, Q., Lu, G., Wu, Y., Yan, J., Shi, Y., Zhang, X. and Gao, G. F. (2017) Cryo-EM structures of MERS-CoV and SARS-CoV spike glycoproteins reveal the dynamic receptor binding domains. Nat. Commun. 8, 15092.

Yurkovetskiy, L., Wang, X., Pascal, K. E., Tomkins-Tinch, C., Nyalile, T. P., Wang, Y., Baum, A., Diehl, W. E., Dauphin, A., Carbone, C., Veinotte, K., Egri, S. B., Schaffner, S. F., Lemieux, J. E., Munro, J. B., Rafique, A., Barve, A., Sabeti, P. C., Kyratsous, C. A., Dudkina, N. V., Shen, K. and Luban, J. (2020) Structural and functional analysis of the D614G SARS-CoV-2 spike protein variant. Cell 183, 739751.e8.

Zhang, J., Cai, Y., Xiao, T., Lu, J., Peng, H., Sterling, S. M., Walsh, R. M., Jr., Rits-Volloch, S., Zhu, H., Woosley, A. N., Yang, W., Sliz, P. and Chen, B. (2021) Structural impact on SARS-CoV-2 spike protein by D614G substitution. Science doi: 10.1126/science.abf2303 [Online ahead of print].

Zhao, Y., Zhao, Z., Wang, Y., Zhou, Y., Ma, Y. and Zuo, W. (2020) Single-cell RNA expression profiling of ACE2, the receptor of SARSCoV-2. Am. J. Respir. Crit. Care Med. 202, 756-759.

Zhou, F., Yu, T., Du, R., Fan, G.,Liu, Y., Liu, Z., Xiang, J., Wang, Y., Song, B., Gu, X., Guan, L., Wei, Y., Li, H., Wu, X., Xu, J., Tu, S., Zhang, Y., Chen, H. and Cao, B. (2020a) Clinical course and risk factors for mortality of adult inpatients with COVID-19 in Wuhan, China: a retrospective cohort study. Lancet 395, 1054-1062.

Zhou, P., Yang, X. L., Wang, X. G., Hu, B., Zhang, L., Zhang, W., Si, H. R., Zhu, Y., Li, B., Huang, C. L., Chen, H. D., Chen, J., Luo, Y., Guo, H., Jiang, R. D., Liu, M. Q., Chen, Y., Shen, X. R., Wang, X., Zheng, X. S., Zhao, K., Chen, Q. J., Deng, F., Liu, L. L., Yan, B., Zhan, F. X., Wang, Y. Y., Xiao, G. F. and Shi, Z. L. (2020b) A pneumonia outbreak associated with a new coronavirus of probable bat origin. Nature 579, 270-273.

Zipeto, D., Palmeira, J., Argañaraz, G. A. and Argañaraz, E. R. (2020) ACE2/ADAM17/TMPRSS2 interplay may be the main risk factor for COVID-19. Front. Immunol. 11, 576745. 